\title{
Arbor
}

\section{La tecnología y la defensa}

\section{Ricardo Torrón Durán}

Arbor CLXV, 651 (Marzo 2000), 509-517 pp.

Desde los albores de la Historia (el Neolitico) ha existido siempre una estrecha relación entre la Tecnología y la Defensa. Esta relación presenta aspectos de gran interés en la primera y segunda Revolución Industrial. Hoy día, introducida ya la $3^{a}$ Revolución Industrial o Era de los Sistemas, el uso de las Nuevas Tecnologías (y principalmente las referentes a la Información / Comunicación) hacen a la sociedad más vulnerable. La Ingeniería Militar no debe ser ajena al planteamiento y solución de este problema.

\section{Evolución histórica}

Entendemos por Tecnología el procedimiento para hacer algo en sentido amplio, es decir, el conjunto de herramientas, sistemas y métodos necesarios para ello. La Real Academia la define como la aplicación del conocimiento para la obtención de resultados prácticos.

La Ingeniería es, por otra parte, el pasar del conocimiento científico al hecho tecnológico. Se trata de, a partir de las ideas y de los conocimientos, llegar con la tecnología adecuada a conseguir los productos $\mathrm{y}$ servicios que los hombres necesitan.

Tratamos aquí de exponer, someramente, la fuerte correlación entre la Tecnología y la Defensa, de cuya manifestación real ha sido protagonista y lo seguirá siendo en el futuro, la Ingeniería Militar.

La historia de los ejércitos, de la evolución de sus capacidades defensivas y ofensivas, es, en buena medida, la historia del cambio técnico. Y ello es así porque la posibilidad de desarrollo de la sociedad 
está ligada a su evolución tecno-económica y ello, a lo largo de los tiempos, se vinculó estrechamente a la posibilidad de defensa y, en ocasiones, de expansión del estatus conseguido, es decir, a las capacidades que para ello disponían los ejércitos.

Para el análisis histórico de esta evolución nos apoyamos en el sugestivo y sugerente símil de las tres olas, presentada por Alvin Toffler.

La Primera Ola se refiere al Neolítico, cuando, hace unos 10.000 años, el hombre descubre y adopta la agricultura y la ganadería. La primera lo conduce al sedentarismo, naciendo así la aldea y, como consecuencia, la defensa organizada, origen remoto de los ejércitos. La segunda le permitirá no sólo aprovechar del animal su carne, leche, piel y huesos, sino también su fuerza como fuente de energía. La aplicación de ambos descubrimientos a las acciones bélicas fue primordial y, en muchas ocasiones, fue la razón de su implantación y desarrollo.

Un aspecto negativo en el proceso social será que a partir de entonces, y como consecuencia de lo apuntado, surge la esclavitud. Al enemigo ya no se le ahuyentará o matará, sino que será más útil como esclavo, del que se aprovechará, sobre todo, su fuerza física, complementando la de los animales estabulados.

La artesanía, es decir, los balbuceos de la ingeniería, que surge en el Neolítico permitirá ya, aunque embrionariamente, analizar el proceder militar del hombre cuando éste se plantea sus necesidades de defensa y ataque. El hombre deberá definir el útil que resuelve sus necesidades en este campo - lo que denominamos sus armaspara obtenerlas, a continuación, a través de un proceso artesanal con la ayuda de medios desarrollados o adaptados por él mismo.

Las tecnologías empleadas, tanto para la obtención como para el uso de dichas armas, estaban basadas principalmente en la fuerza muscular del hombre o de sus animales.

Aparecen, así, la honda, la jabalina, la espada, la lanza, el casco, el escudo, el arco, la rueda, la silla de montar, la catapulta, la ballesta y un largo etcétera. Al mismo tiempo surgen la castrametación y las técnicas de fortificación.

Al final de esta Era Agrícola (la que es fruto de la Primera Ola) aparece la pólvora y las armas que la usan (bombardas, mosquetes, arcabuces) revolucionan el Arte de la Guerra. Las tecnologías basadas en la pólvora se añaden, modifican, y mejoran las tecnologías basadas en la fuerza muscular. La fortificación, por su parte, sufre la consiguiente transformación. 


\section{La tecnología y la defensa}

La Segunda Ola coincide con la Revolución Industrial. La Ingeniería y la Tecnología no sólo, a partir de entonces, tienen la acepción actual, sino que también la sociedad y la cultura del mundo occidental, en la que estamos inmersos, tienen en ella la causa de su origen y de su evolución económica.

La interrelación entre lo militar y lo tecnológico se manifiesta plenamente y no se puede, a partir de entonces, hacer un análisis profundo de ninguno de estos campos sin tener el otro presente.

La Revolución Industrial, es dividida generalmente en tres fases $\left(1^{\mathrm{a}}, 2^{\mathrm{a}}\right.$ y $3^{\mathrm{a}}$ Revolución Industrial), siguiéndose para esta clasificación los criterios de los recursos empleados, incluidas las fuentes de energía, y los sectores punta de la producción industrial.

En la $1^{a}$ Revolución Industrial, que abarca el final del siglo XVIII y prácticamente todo el XIX, las fuentes de energía pasaron a ser el carbón y la máquina de vapor, sustituyendo la energía animal que se mantenía casi como única desde el Neolítico. El sector punta pasa del textil al metalúrgico, que actúa como motor del resto del sector productivo.

Por ello, además de la evolución de las armas de fuego que es espectacular, surgen las plataformas modernas (vehículos, ferrocarril, navíos) al tiempo que se sustituye la vela y el animal por el vapor y la madera, el barro y la piedra por el hierro.

La conjunción del desarrollo en los campos metalúrgico y mecánico con el químico (pólvoras y explosivos) provoca el desarrollo de la ciencia balística y artillera, que cubre necesidades planteadas en el campo de batalla con las nuevas doctrinas de empleo de los ejércitos, en especial, desde las guerras napoleónicas.

La $2^{a}$ Revolución Industrial surge cuando, con la invención de la turbina y del motor de explosión, se generaliza el empleo de la electricidad y del petróleo como fuentes de energía. Los sectores punta pasan a ser el petroquímico, el de material eléctrico, el de máquinas herramientas, el de automoción, etc.

Se realiza, entonces, la revolución de los transportes, tanto terrestres como marítimos y aéreos, y se introducen las técnicas y medios de comunicación a distancia (radio, teléfono, T.V.)

Este período cubre básicamente los dos primeros tercios de este siglo e incluye, por tanto, las dos Guerras Mundiales y buena parte de la llamada Guerra Fría. La relación Tecnología/Defensa se pone de manifiesto en cada aportación científica, en cada proyecto de investigación, en cada desarrollo.

La lista de productos que nacen como consecuencia de una necesidad militar o que inmediatamente se reflexiona sobre su aplicación bélica 
es enorme: los nuevos aceros, el telégrafo, el teléfono, la radiotransmisión, la radiogonometría, el submarino, el telémetro, la válvula de vacío, el nylon, el transistor, el circuito integrado, el radar, la misilística, el sonar, los ordenadores, el láser, el neumático, el uso del infrarrojo, los satélites, la fibra óptica, la turbina de gas, el helicóptero, el motor de reacción, la ergonomía, la aviónica, la propulsión nuclear, el tratamiento de datos, la criptografía , el GPS, la digitalización, la robótica, etc., etc.

También es en esta fase cuando se desarrolla la organización científica del trabajo, tan próxima a la labor del ingeniero militar. Como antes dijimos, también es tecnología el procedimiento, la manera de hacer y de decidir, el método en suma. La participación de los militares en la ayuda a la toma de decisiones ante un problema complejo, como son los de defensa y ataque, se plasmó en el nacimiento de la Investigación Operativa en la $2^{\mathrm{a}}$ Guerra Mundial y, posteriormente, en su desarrollo durante la Guerra Fría.

Por último, la $3^{a}$ Revolución Industrial la estamos empezando a vivir en nuestros días. Aparece la información como recurso y a las fuentes de energía anteriores se unen la nuclear y las llamadas energías renovables. Surgen, por otra parte, las denominadas Nuevas Tecnologías (los nuevos materiales, la biotecnología, las nuevas tecnologías de la información).

Esta $3^{\text {a }}$ Revolución Industrial coincide con la Tercera Ola de Toffler. Nace una nueva cultura, la de la sociedad post-industrial, también llamada Sociedad de la Información. A la vez una nueva era surge: La Era de los Sistemas. Dediquemos una reflexión sobre ella antes de extendernos en su relación e implicaciones con la Defensa.

\section{La era de los sistemas}

La nueva percepción de los fenómenos organizativos, la utilización de las nuevas redes de comunicación en la toma de decisiones, el acceso a la información procesada y al conocimiento, la posibilidad de la exploración del futuro plural e incierto y el tratamiento holístico de los problemas (todo ello auspiciado por las Nuevas Tecnologías) abundan en favor de la denominación de la Era de los Sistemas a la era que ahora se inicia, con el entrechocar de la Segunda Ola en retirada y el empuje vigoroso, creciente por momentos, de la Tercera. 
Observemos el papel que juegan las Nuevas Tecnologías en la Era de los Sistemas. Para ello nos apoyamos en el «Sistema Técnico» constituido por los cuatro pilares siguientes:

- Los seres vivos

- La materia

- La energía

- La información

(En las líneas anteriores ya expusimos que la tecnología militar de la Primera Ola se fundamentaba en la fuerza física de los seres vivos; en la Segunda Ola ( $1^{\mathrm{a}}$ y $2^{\mathrm{a}}$ Revolución Industrial) lo hacía en la materia y la energía fundamentalmente; y es ahora, en la Tercera Ola, cuando lo hace, básicamente, en el nuevo recurso tecnológico: la información).

Las Nuevas Tecnologías aparecen no solo en el último pilar citado y, así, los progresos en la ciencia de los seres vivos son el origen de la nueva Biotecnología, que se encuentra en la fase inicial de un desarrollo que afectará a numerosos sistemas correspondientes a sectores económicos de la industria y de los servicios (la agroalimentación, la sanidad, la ecología, las fuentes de energía), pero también directamente al sector de la defensa (la guerra bacteriológica, la preservación del impacto medioambiental, la profilaxis y prevención de heridos, etc.).

Respecto a la materia, existe una nueva generación de materiales compuestos que aportan cambios muy importantes al desarrollo de sistemas físicos y químicos de sofisticación creciente en el campo de numerosas ingenierías: de telecomunicaciones, de productos químicos, automovilística y, muy particularmente, la de guerra, la espacial y la aeronáutica.

En el tercer pilar, la energía, surge como nueva tecnología la nuclear (principalmente la de fusión) y la de nuevos recursos naturales renovables que se incorporan al sistema energético. Las consecuencias industriales, económicas, ecológicas y de seguridad y defensa son uno de los temas políticos-sociales punteros de nuestros días.

Pues bien, a pesar de la trascendencia de estos cambios, los más importantes en extensión y profundidad, bajo el punto de vista social, económico, político y de defensa, los van a proporcionar las Nuevas Tecnologías de la Información / Comunicación que van a utilizar el nuevo recurso, ya reiteradamente citado: la información.

$Y$ es que la información, al igual que la materia y la energía, se obtiene, se capta, se procesa, se transporta y se almacena. Es decir, que acepta un tratamiento «ingenieril». Las Nuevas Tecnologías que la tratan son la microelectrónica, las telecomunicaciones, la informática, 
la robótica y la automatización. Su desarrollo es espectacular. Sus efectos sociales no han hecho más que empezar y pronto será cotidiano que nuestros sistemas informáticos de comunicaciones, de mando $\mathrm{y}$ control, de ayuda a la decisión, etc., incorporen el uso de la llamada «inteligencia artificial», con la lectura automática de todo tipo de caracteres, la traducción correcta de lenguas, la comunicación directa oral o escrita con la máquina, la generalización del uso de los sistemas expertos que tratan conocimiento además de datos y la desaparición práctica, a la hora de comunicarse, de las distancias geográficas.

No pretendemos exponer con detalle la emergencia del nuevo sistema tecnológico, pero sí señalar que los sistemas que surgen de los cuatro pilares básicos están estrechamente relacionados. Así los sistemas biotecnológicos le deben mucho a la microelectrónica, los sistemas de telecomunicación a los nuevos materiales, y así sucesivamente.

Y sobrevolando esta interrelación está el papel de aglutinante y de efecto multiplicador que ejercen las Nuevas Tecnologías de la Información sobre las demás, así como sus consecuencias económicas, sociales y culturales, dando origen a la llamada Sociedad de la Información.

Si tomamos como definición de sistema, la suministrada por Bertalanffy que, a pesar de su sencillez es siempre válida: «conjunto dinámico de elementos y de relaciones entre estos elementos», podemos decir que las Nuevas Tecnologías de la Información han establecido, modificado, reforzado o refinado las relaciones entre los elementos de los más diversos sistemas diseñados por el hombre, sean físicos o abstractos, así como de aquellos organizativos basados en la actividad humana. Ello explica, de una manera sencilla, que hablar de Información y de sus Tecnologías es lo mismo que hablar de Sistemas, y que, por tanto, esta Sociedad de la Información aparece en la Era de los Sistemas, fruto de la Tercera Ola.

\section{La defensa en la sociedad de la información}

Es frecuente hablar hoy día de la revolución de lo militar y, en efecto, casi todo lo concerniente a la defensa está experimentando un cambio, que," en ocasiones, es radical.

Este cambio, unido a la interdependencia, la globalización, la complejidad y la incertidumbre, configura el paradigma que enmarca, hoy día, toda decisión en el campo de la seguridad y de la defensa. 
La implantación de las Nuevas Tecnologías de la Información en el ámbito militar, igual que en la sociedad en general como ya hemos dicho, es uno de los principales factores desencadenantes del citado cambio, pero también con ellas tenemos el instrumento que, adecuadamente usado, permite adaptarse, preverlo, dominarlo, provocarlo o adelantarse a él.

Ahora bien, en el campo de la defensa, el diseño, la implantación y la utilización de las Nuevas Tecnologías de la Información revisten especiales aspectos relacionados con el análisis y la evaluación de las posibles amenazas, los nuevos desafíos, el control de las crisis, la toma de decisiones, la formación, el adiestramiento y la instrucción de los mandos y las unidades, el mando y la conducción de las operaciones, la rapidez y la acertada respuesta ante determinadas situaciones, las nuevas capacidades exigidas a los ejércitos y la garantía de la seguridad y calidad en el empleo de dichas tecnologías.

Por otra parte, la necesidad de la relación con los medios de comunicación, así como con el resto de la sociedad y de los organismos del Estado, unida a la profesionalización de nuestros ejércitos y a las misiones internacionales a ellos encomendadas, exigen una coordinación en la implantación de los Sistemas de Información y Telecomunicaciones, con implicaciones que llegan al más alto nivel de decisión.

Dichos sistemas son la base de los Sistemas de Mando y Control, con necesidades crecientes de interoperabilidad, flexibilidad y modularidad, como seguramente nunca han sido exigidas a ningún sistema creado por el hombre.

Por ello, es necesaria la exigencia a los responsables de la implantación y de la adecuada utilización de las Nuevas Tecnologías de la Información en el ámbito de la defensa - es decir, tanto al planificador como al ingeniero- de adoptar una actitud nueva, que parta del convencimiento de la necesidad del cambio y le permita asumir un papel de protagonista frente al futuro.

Esta actitud, que se ha llegado a llamar «espíritu de frontera», como heredera del espíritu exploratorio geográfico de otras épocas, es la actitud prospectiva cara al futuro.

La Prospectiva surge hoy día como un útil imprescindible para el planificador al suministrarle la metodología de exploración de los futuros posibles, para seleccionar, así, aquél preferido entre los posibles realizables.

En realidad, como ya hemos dicho más arriba respecto a la Investigación Operativa, la Prospectiva no es más que una tecnología que se incorpora al resto de las Nuevas Tecnologías de la Información. 
Permite, además, irse adaptando a la evolución de los acontecimientos pues, aunque considera siempre el futuro como plural e incierto, ayuda al decisor a definir, tanto las acciones de configuración del futuro al que aspira, como las de compensación de los efectos nocivos provocados por el acaecimiento de sucesos perjudiciales a sus intereses.

La actitud prospectiva exige, por otra parte, el enfoque sistémico de los problemas, en contraposición al principio reduccionista que desde la Segunda Ola marcó la pauta para enfrentarse a la complejidad y que hoy, en la Era de los Sistemas, resulta claramente insuficiente.

Ambas actitudes, la prospectiva y la sistémica, son la base filosófica de la línea de pensamiento que, creemos, debe presidir nuestras decisiones en el campo de la seguridad y de la defensa que nos permita la acertada implantación y la adecuada utilización de las Nuevas Tecnologías de la Información.

Pues bien, este enfoque prospectivo y sistémico exige la consideración, bajo el punto de vista de la defensa, no sólo de los Sistemas de Información y Telecomunicaciones de las unidades militares y de los organismos de la defensa sino de toda la sociedad.

Es decir, en nuestra época, en la Sociedad de la Información, la imbricación entre la Tecnología y la Defensa no está solamente en la concepción y el desarrollo de las tecnologías, como en épocas anteriores, sino en su posterior uso, tanto militar como civil.

Determinados autores han prevenido ya sobre la Guerra de la Información. La vulnerabilidad de los Sistemas de Información pasa a ser motivo de creciente atención, pues es fácil imaginar las consecuencias catastróficas de la destrucción o del sabotaje de un sistema informático crítico o de una red de telecomunicaciones vital para la supervivencia de un País.

A medida que la Sociedad de la Información se implanta, el número de puntos vitales crece espectacularmente y su vulnerabilidad total aumenta.

Creemos pues que, al igual que en la Era Agrícola (Primera Ola) los ejércitos se debían ocupar no solo de combatir al enemigo, sino también de la protección de las personas, los cultivos y la ganadería; y en la Era Industrial (Segunda Ola) las instalaciones fabriles pasan a ser objetivos prioritarios del enemigo y, como consecuencia, motivo de custodia y protección; análogamente, en esta Era de los Sistemas, fruto de la Tercera Ola, donde se implantan las Nuevas Tecnologías de la Información, los variados sistemas que se generan, deberán ser motivo de atención por los responsables de la defensa, con intervención activa de la Ingeniería Militar, que con su actitud prospectiva y sis- 


\section{La tecnología y la defensa}

témica, habrá participado en su diseño, implantación estratégica y adecuada utilización.

\section{Bibliografía}

Ricardo ToRrón. El Análisis de Sistemas. Monografía nº 16 sobre Ingeniería de Sistemas. ISDEFE. 1997

Carlos Martí. Tecnología de la Defensa. ISDEFE. 1999.

"Tendencias». Boletín 2/99 del MADOC.

Alvin Tofrler. La Tercera Ola. Plaza y Janés. 1980.

Alvin and Heidi Toffler. War and antiwar. Warner Books. 1993. 